\title{
Effect of music interventions on anxiety during labor: a systematic review and meta-analysis of randomized controlled trials
}

\author{
Hsin-Hui Lin ${ }^{1}$, Yu-Chen Chang ${ }^{1}$, Hsiao-Hui Chou ${ }^{1}$, Chih-Po Chang ${ }^{1}$, Ming-Yuan Huang ${ }^{2}$, Shu-Jung Liu ${ }^{3}$, Chin- \\ Han Tsai ${ }^{4}$, Wei-Te Lei ${ }^{\text {Corresp., } 5,6}$, Tzu-Lin Yeh ${ }^{\text {Corresp. 7, } 8}$

Background. Anxiety is commonly experienced during the delivery process and has shown to have adverse effects on maternal and infant health outcomes. Music interventions tend to reduce the effects of anxiety in diversity populations, are low cost, are easily accessible, and have high acceptability. The aim of this review and meta-analysis was to assess the effectiveness of music interventions in reducing anxiety levels among women during labor.

Methods. Seven databases from inception to the end of December, 2018, without any language or time restriction including Embase, PubMed, the Cochrane Library, the Cumulative Index to Nursing and Allied Health, PsycINFO, Airiti Library, and PerioPath: Index to Taiwan Periodical Literature were searched using key terms related to pregnancy, anxiety, and music. Randomized controlled trials that assessed the effect of music during labor and measured anxiety levels as an outcome were included. Meta-analyses were conducted to assess anxiety reduction following a music intervention compared to that after placebo treatment.

Results. A total of 14 studies that investigated a total of 1,310 participants were included in this review. The meta-analyses indicated that those in the intervention group had a significant decrease in anxiety scores (standardized mean difference $(\mathrm{SMD})=-2.40,95 \%$ confidence interval $[\mathrm{Cl}]=-3.29$ to $-1.52, p$ $<0.001 ; I^{2}=97.66 \%$ ), heart rate (HR) (difference in means $=-3.04$ beats $/ \mathrm{min}, 95 \% \mathrm{Cl}=-4.79$ to -1.29 beats $/ \mathrm{min}, p=0.001 ; I^{2}=0.00 \%$ ), systolic blood pressure (SBP) (difference in means $=-3.71 \mathrm{mmHg}$, $95 \% \mathrm{Cl}=-7.07$ to $-0.35 \mathrm{mmHg}, p=0.031 ; l^{2}=58.47 \%$ ), and diastolic blood pressure (DBP) (difference in means $=-3.54 \mathrm{mmHg}, 95 \% \mathrm{Cl}=-5.27$ to $-1.81 \mathrm{mmHg}, p<0.001 ; I^{2}=0.00 \%$ ) as compared to the women in the control group.

Conclusions. Music interventions may decrease anxiety scores and physiological indexes related to anxiety (HR, SBP, and DBP). Music interventions may be a good non-pharmacological approach for decreasing anxiety levels during labor.

Peer) reviewing PDF | (2019:01:34693:2:0:NEW 10 Apr 2019) 
1 Effect of Music Interventions on Anxiety during Labor:

2 A Systematic Review and Meta-analysis of

3 Randomized Controlled Trials

${ }^{1}$ Department of Family Medicine, MacKay Memorial Hospital, Taipei, Taiwan

${ }^{2}$ Department of Hospice and Palliative Care, MacKay Memorial Hospital, Tamsui Branch, New 10 Taipei City, Taiwan

$11{ }^{3}$ Department of Medical Library, MacKay Memorial Hospital, Tamsui Branch, New Taipei City, 12 Taiwan

$13{ }^{4}$ Department of gynecology and obstetrics, Hsinchu MacKay Memorial Hospital, Hsinchu, 14 Taiwan

$15{ }^{5}$ Department of Pediatrics, Hsinchu MacKay Memorial Hospital, Hsinchu, Taiwan

$16{ }^{6}$ Graduate Institute of Clinical Medical Sciences, College of Medicine, Chang Gung University, 17 Taoyuan City, Taiwan

$18{ }^{7}$ Department of Family Medicine, Hsinchu MacKay Memorial Hospital, Hsinchu, Taiwan

$19{ }^{8}$ Institute of Epidemiology and Preventive Medicine, National Taiwan University, Taipei,

20 Taiwan

Corresponding author 1:

Tzu-Lin $\mathrm{Yeh}^{7,8}$

The Department of Family Medicine, Hsinchu MacKay Memorial Hospital, Number 690,

Corresponding author 2 :

29 Wei-Te Lei ${ }^{5,6}$ 
36

37

38

39

40

41

42

43

44

45

46

47

48

49

50

51

52

53

54

55

56

57

58

59

60

61

62

63

64

65

66

67

68

69

70

71

72

73

74

\section{Abstract}

Background. Anxiety is commonly experienced during the delivery process and has shown to have adverse effects on maternal and infant health outcomes. Music interventions tend to reduce the effects of anxiety in diversity populations, are low cost, are easily accessible, and have high acceptability. The aim of this review and meta-analysis was to assess the effectiveness of music interventions in reducing anxiety levels among women during labor.

Methods. Seven databases from inception to the end of December, 2018, without any language or time restriction including Embase, PubMed, the Cochrane Library, the Cumulative Index to Nursing and Allied Health, PsycINFO, Airiti Library, and PerioPath: Index to Taiwan Periodical Literature were searched using key terms related to pregnancy, anxiety, and music. Randomized controlled trials that assessed the effect of music during labor and measured anxiety levels as an outcome were included. Meta-analyses were conducted to assess anxiety reduction following a music intervention compared to that after placebo treatment.

Results. A total of 14 studies that investigated a total of 1,310 participants were included in this review. The meta-analyses indicated that those in the intervention group had a significant decrease in anxiety scores (standardized mean difference (SMD) $=-2.40,95 \%$ confidence interval $[\mathrm{CI}]=-3.29$ to $-1.52, p<0.001 ; I^{2}=97.66 \%$ ), heart rate $(\mathrm{HR})$ (difference in means $=$ -3.04 beats $/ \mathrm{min}, 95 \% \mathrm{CI}=-4.79$ to -1.29 beats $/ \mathrm{min}, p=0.001 ; I^{2}=0.00 \%$ ), systolic blood pressure $(\mathrm{SBP})$ (difference in means $=-3.71 \mathrm{mmHg}, 95 \% \mathrm{CI}=-7.07$ to $-0.35 \mathrm{mmHg}, p=$ $0.031 ; I^{2}=58.47 \%$ ), and diastolic blood pressure (DBP) (difference in means $=-3.54 \mathrm{mmHg}$, $95 \% \mathrm{CI}=-5.27$ to $\left.-1.81 \mathrm{mmHg}, p<0.001 ; I^{2}=0.00 \%\right)$ as compared to the women in the control group.

Conclusions. Music interventions may decrease anxiety scores and physiological indexes related to anxiety (HR, SBP, and DBP). Music interventions may be a good non-pharmacological approach for decreasing anxiety levels during labor.

\section{Introduction}

During pregnancy and labor, women experience psychological and physiological changes that generate stress (Cardwell 2013). With the progression of labor, women experience increasing anxiety during labor; which has a negative effect on the mother as well as the newborn baby (Zijlmans et al. 2017). The prevalence of anxiety among prenatal women is higher than in the general population ( $27 \%$ compared to $5 \%$ ), and there was significantly higher complication rates in anxious women (Zhao M 1999). There might be more postpartum psychiatric symptoms, decreased sexual functioning, less willing for a next child, and poor mother-infant connection when mothers had more negative childbirth experiences during labor (Goodman 2004). In addition, high anxiety levels may also lead to negative outcomes in women undergoing cesarean section (CS), including higher analgesic consumption, elevated blood pressure (BP), elevated heart rate (HR), increased cortisol level, reduced immune response, slower wound healing, and higher infection risk (Gorkem et al. 2016; Hepp et al. 2016; Scott 2004). 
75

76

77

78

79

80

81

82

83

84

85

86

87

88

89

90

91

92

93

94

95

96

97

98

99

100

101

102

103

104

105

106

107

108

109

110

111

112

113

114

115

Music is an ancient healing practice that can inspire the soul as well as improve immunity, forming a powerful therapy (Lane 1992). Listening to music reduces the catecholamine levels, thus improving physical health status, decreasing stress hormones, and stabilizing vital signs (Liu et al. 2010; Mok \& Wong 2003). Moreover, music interventions have an effect in decreasing pain, anxiety, and analgesic consumption in previous studies (Ikonomidou et al. 2004; Siedliecki \& Good 2006; Smolen et al. 2002). In medical care, music interventions may include music listening initiated by patients, music medicine (listening to prerecorded music offered by medical staff for symptom management), and music therapy (individualized music interventions including listening to live, or prerecorded music, playing instruments and composing music offered by a trained therapist) (Bradt et al. 2015).

Most relaxants and antidepressants cross the placental barrier and have negative effects on the fetus; therefore, establishing of alternative non-pharmaceutical interventions to reduce anxiety in pregnant women is important. A recent Cochrane Database Systematic Review has shown that music-based interventions may reduce anxiety during pregnancy (Corbijn van Willenswaard et al. 2017). However, the evidence regarding the efficacy of music interventions during labor on the reduction of anxiety is inconclusive. One study has shown that music intervention has a significant positive effect on anxiety and pain during the latent phase of labor (Liu et al. 2010). Another study has reported that music intervention during CS does not significantly change the anxiety score (Reza et al. 2007). One publication has revealed significantly lower anxiety and higher satisfaction level after music intervention during CS; however, there was no significant difference in any of the physiological indexes (Chang \& Chen 2005). Therefore, we conducted this systematic review and meta-analysis to evaluate the effectiveness of music interventions in reducing the anxiety levels of women undergoing labor.

\section{Materials \& Methods}

\section{Search Strategy}

The review protocol has been registered in the PROSPERO International Prospective Register of Systematic Reviews (registration number: CRD42018108267) and was written according to the Preferred Reporting Items for Systematic Reviews and Meta-Analyses (PRISMA) statement (Liberati et al. 2009) (Table S1).

Seven databases were searched from inception to the end of December, 2018, without any language or time restriction including Embase, PubMed, the Cochrane Library, the Cumulative Index to Nursing and Allied Health (CINAHL), PsycINFO, Airiti Library, and PerioPath: Index to Taiwan Periodical Literature. A professional librarian reviewed the terms and organized them in the optimal manner to make the search strategy sensitive and specific.

The search key terms were "labor," "music," "anxiety," and "stress." Keywords were combined using Boolean searches, and the search was performed using keywords, Boolean operators, and MeSH descriptors. The details of search strategy have been described in Table S2.

\section{Selection of Studies}

Two authors (HHL and MYH) screened the title and abstract of each study that met the inclusion criteria independently, and the controversies were resolved through discussions with the third 
116 author (TLY). Two independent reviewers (HHL and TLY) assessed the eligibility of each 117 publication after the initial search. The inclusion criteria of selected randomized control trials 118 (RCT) were as follows: 1) studies on women who underwent vaginal or CS delivery, either nulliparous or multiparous, of normal term, singleton gestation; 2) at least one treatment group wherein music intervention was applied during the labor process; 3) inclusion of a placebo group as control; and 4) reporting of anxiety status after the intervention. We excluded the following: 1) studies on women with deafness (unless corrected with a hearing aid), high risk of pregnancy, or severe psychiatric disorder; 2) duplicate publications; 3) crossover study designed trials; and 4) studies with an effective intervention as control arm rather than a placebo.

125

126

127

128

129

130

131

132

133

134

135

136

137

138

139

140

141

142

143

144

145

146

147

148

149

150

151

152

153

154

155

156

\section{Data Extraction}

Two authors (HHL and WTL) independently extracted the data, and the inconsistencies were resolved through discussion. The following information was collected (Table 1): first author's name, year of publication, country of publication, number of participants, age of participants, number of participants in the intervention and control groups, details of the intervention (including the music types, time, and duration), and clinical outcome measures (including the time of the outcome in relation to the treatment). The primary outcome was the anxiety status, measured using the recognized rating scales, including visual analog scale for anxiety (VAS-A), state-trait anxiety inventory (STAI) and self-rating anxiety scale (SAS). VAS-A is a scale comprising a $10 \mathrm{~cm}$ line on which the participant marks her current degree of anxiety, with the left end of the line being labeled "no anxiety" and the right end being labelled "maximum anxiety". The scale is scored by measuring the distance of the mark from the left end. (Hornblow \& Kidson 1976). The outcome was measured after the delivery process. The secondary outcomes were physical signs, including systolic blood pressure (SBP), diastolic blood pressure (DBP), and heart rate (HR).

\section{Assessment of the Risk of Bias in the Included Studies}

Three reviewers (YCC, HHC, and CPC) independently assessed the risk of bias using the Cochrane Review risk of bias assessment tool. Conflicts were resolved through discussion. We assessed sequence generation (selection bias), allocation sequence concealment (selection bias), blinding of participants and personnel (performance bias), blinding of outcome assessment (detection bias), incomplete outcome data (attrition bias), selective outcome reporting (reporting bias), and other potential sources of bias (Table S3).

\section{Statistical Analyses}

Comprehensive meta-analysis software (version 3.0, Biostat, Englewood, NJ, USA) was used for the analyses. There was significant (and expected) heterogeneity among the studies; therefore, a random effects model was selected (Higgins \& Thompson 2002). Pooled estimates were calculated with $95 \%$ confidence intervals (CIs). Statistical heterogeneity was assessed using $I^{2}$ and Cochran's $\mathrm{Q}$ tests. A $p$ value of $<0.10$ for the $\chi^{2}$ test of the Q statistic or an $I^{2}$ of $>50 \%$ was considered indicative of statistically significant heterogeneity (Higgins et al. 2003). A sensitivity analysis was performed by repeating the analysis after sequential exclusion of one study at a time to observe the effect on the overall results. Potential publication bias was evaluated by observing the symmetry of the funnel plots and using Egger's test (Egger et al. 1997). Furthermore, subgroup analysis was performed to further analyze the effects of clinical variables as the possible origins 
157 of heterogeneity, such as ways of delivery, and types of music. Finally, meta-regression analyses

158

159

160

161

162

163

164

165

166

167

168

169

170

171

172

173

174

175

176

177

178

179

180

181

182

183

184

185

186

187

188

189

190

191

192

193

194

195

196

were performed only when the data could be assessed throughout more than five trials.

\section{Results}

\section{Description of Studies and Quality Assessment}

Database searches identified 1,460 studies, of which 299 were duplicates (Figure 1). Finally, 14 publications were included in our qualitative synthesis and critical review (Table 1) (Blackburn et al. 2011; Chang \& Chen 2005; Choubsaz et al. 2018; Gokyildiz Surucu et al. 2018; Hepp et al. 2018; Karkal et al. 2017; Kushnir et al. 2012; Lee et al. 2004; Li \& Dong 2012; Liu et al. 2010; Reza et al. 2007; Simavli et al. 2014a; Simavli et al. 2014b; Wan \& Wen 2018). All these studies, except one from the US and one recently published study from Germany, were conducted in Asia; of these, six were performed in the Middle Asia. The sample sizes ranged from 50 to 304 . The mean age of the participants ranged from 23.8 to 33.6 years. All the studies included women who were at low risk. Eight studies investigated pregnant women undergoing CS.

All the interventions involved listening to music. In most studies, sedative, relaxing, stable and regular rhythmic patterns were recommended or chosen as the music types. Specific musical pieces or songs (the Four Seasons by Vivaldi and lullaby by Mozart) were mentioned in one study. The use of traditional music, such as Turkish music (Acemasiran mode), Spanish style guitar, Israeli tunes, and Chinese religious music, were mentioned in six studies. Self-selected music under recommendation was used in most studies (nine studies; no clear information in two studies).

The time of the music intervention included the latent phase, active phase, and whole stages of labor in studies for participants undergoing normal spontaneous delivery (NSD) and before entering the operation room and during the operation for participants undergoing CS. For participants undergoing NSD, the intervention duration varied from at least 30 minutes to 20-minutes break per 1-2 hours during all the labor stages and from 40 minutes before the surgery to the entire operation duration since entering operation room to the end of surgery for participants undergoing CS.

The VAS-A was used to assess the anxiety status in seven studies, STAI was used in four studies, and Zung's SAS was used in two studies. Physiological indexes, such as SBP, DBP, RR, $\mathrm{HR}$, and $\mathrm{SpO}_{2}$ were recorded in six studies. HRV was tested in one study and cortisol level was used in two other studies. The timing of the outcome assessment varied from right after intervention to 24 hours after the intervention in the NSD group and 6 hours after the operation in the CS group.

A total of 1,310 participants were enrolled in these studies. Majority of the included studies had a low to moderate potential for bias, as demonstrated by our quality assessment using the Cochrane assessment tool (Table S3).

All the studies compared the intervention and control groups; however, one study incorporated a four-arm design, with two additional groups receiving acupressure intervention as well as 
197

198

199

200

201

202

203

204

205

206

207

208

209

210

211

212

213

214

215

216

217

218

219

220

221

222

223

224

225

226

227

228

229

230

231

232

233

234

235

acupressure and music combined treatment (Wan \& Wen 2018); one study used a three-arm design, with one additional ear-plug group (Choubsaz et al. 2018).

\section{Data Synthesis and Meta-Analyses}

We focused on the effect of music intervention on the change in the anxiety status. Data pertaining to anxiety evaluated using recognized rating scales including VAS-A, STAI, and SAS and physiological indexes were extracted for further meta-analyses. Studies with different outcome measurements, such as pain scores, depression scores, and satisfaction scores, were excluded. VAS-A was measured in seven studies, STAI in four, SAS in two, and HR and BP in six. However, data from some of the studies (Liu et al., Gokyildiz Surucu et al., and Kushnir et al.) were not available because the outcomes were measured before delivery, rather than postdelivery. Moreover, data from Choubsaz et al. was not usable due to uneven pre-test condition. We also excluded Blackburn et al. due to insufficient data. Finally, nine studies were included for anxiety level meta-analysis (Chang \& Chen 2005; Gokyildiz Surucu et al. 2018; Hepp et al. 2018; Karkal et al. 2017; Li \& Dong 2012; Reza et al. 2007; Simavli et al. 2014a; Simavli et al. 2014b; Wan \& Wen 2018) and four studies (Chang \& Chen 2005; Hepp et al. 2018; Lee et al. 2004; Simavli et al. 2014a) for BP and HR meta-analysis. Ultimately, 10 studies with a combined study population of 1,080 participants were included in our meta-analysis.

\section{Primary Outcome}

In nine selected studies, the anxiety level of 519 participants in the music intervention group decreased $\left(\mathrm{SMD}=-2.40,95 \% \mathrm{CI}=-3.29\right.$ to $-1.52, p<0.001 ; I^{2}=97.66 \%$; Figure 2 ) as compared to that in the 511 participants in the placebo group. Although there was publication bias $[t(8)=4.41, P=0.002]$, the results of the meta-analysis did not change (SMD $=-4.12,95 \%$ $\mathrm{CI}=-5.93$ to -2.31 ) after the trim and fill test (with three potentially missing studies to the left of the mean). The significance remained unchanged after removing any of the studies. Among these nine studies, five were on pregnant women undergoing NSD, and four were on those scheduled for CS. A subgroup analysis, based on the methods of delivery, showed a significant decrease in the anxiety score with music intervention in both, the NSD group (SMD $=-4.69$, $95 \% \mathrm{CI}=-6.28$ to $\left.-3.10, p<0.001 ; I^{2}=96.63 \%\right)$ and $\mathrm{CS}$ group $(\mathrm{SMD}=-0.70,95 \% \mathrm{CI}=$ -1.18 to $-0.22, p=0.004 ; I^{2}=89.69 \%$; Figure 3 ). Another subgroup analysis by music types showed significant differences if music types were chosen by the participants (SMD $=-1.71$, $95 \% \mathrm{CI}=-2.59$ to $0.82, p<0.001 ; I^{2}=97.48 \%$; Figure 4 ).

\section{Secondary Outcome}

Combining the results of four studies in relation to physiological indexes, the meta-analysis indicated that those in the intervention group exhibited a significant decrease in the HR (difference in means $=-3.04$ beats $/ \mathrm{min}, 95 \% \mathrm{CI}=-4.79$ to -1.29 beats $/ \mathrm{min}, p=0.001 ; I^{2}=$ $0.00 \%$; Figure 5), SBP (difference in means $=-3.71 \mathrm{mmHg}, 95 \% \mathrm{CI}=-7.07$ to $-0.35 \mathrm{mmHg}, p$ 
$236=0.031 ; I^{2}=58.47 \%$; Figure 6 ), and DBP (difference in means $=-3.54 \mathrm{mmHg}, 95 \% \mathrm{CI}=-5.27$

237 to $-1.81 \mathrm{mmHg}, p<0.001 ; P^{2}=0.00 \%$; Figure 7 ).

238 Subgroup analyses by methods of delivery showed that in the CS group, HR and DBP decreased 239 significantly (HR: difference in means $=-2.97$ beats $/ \mathrm{min}, 95 \% \mathrm{CI}=-4.80$ to -1.15 beats $/ \mathrm{min}, p$ $240=0.001 ; I^{2}=0.00 \%$; Figure S1a and DBP: difference in means $=-3.02 \mathrm{mmHg}, 95 \% \mathrm{CI}=-5.49$

241 to $-0.54 \mathrm{mmHg}, p=0.017 ; P^{2}=0.00 \%$; Figure S1c). However, the SBP did not decrease

242 significantly (difference in means $=-2.96 \mathrm{mmHg}, 95 \% \mathrm{CI}=-7.15$ to $1.23 \mathrm{mmHg}, p=0.166 ; I^{2}$ $243=54.40 \%$; Figure S1b).

244 Subgroup analyses by music types showed that if the music type was chosen by the participants, 245 HR and DBP significantly decreased (HR: difference in means $=-2.85$ beats $/ \mathrm{min}, 95 \% \mathrm{CI}=$ $246-4.69$ to -1.02 beats $/ \mathrm{min}, p=0.002 ; I^{2}=00.00 \%$; Figure S1d and DBP: difference in means $=$ $247-3.48 \mathrm{mmHg}, 95 \% \mathrm{CI}=-5.32$ to $-1.65 \mathrm{mmHg}, p<0.001 ; l^{2}=00.00 \%$; Figure $\mathrm{S} 1 \mathrm{f}$ ). However, 248 the SBP did not decrease significantly (difference in means $=-3.09 \mathrm{mmHg}, 95 \% \mathrm{CI}=-7.17$ to $2490.99 \mathrm{mmHg}, p=0.137 ; I^{2}=65.03 \%$; Figure S1e).

250 There was no publication bias $[\mathrm{t}(2)=1.98,0.94$, and $0.20 ; p=0.19,0.44$, and 0.86 for HR, SBP, 251 and DBP, respectively]. However, after removing data from either of the studies, except one 252 study (Hepp et al. 2018) that included the largest population, the change in SBP was not 253 significantly different between the music intervention and placebo groups (Simvali, Gumus et al: 254 difference in means $=-2.96 \mathrm{mmHg}, 95 \% \mathrm{CI}=-7.15$ to $1.23 \mathrm{mmHg}, p=0.166$; Chang et al: 255 difference in means $=-3.62 \mathrm{mmHg}, 95 \% \mathrm{CI}=-7.66$ to $0.41 \mathrm{mmHg}, p=0.078$; and Lee et al: 256 difference in means $=-3.09 \mathrm{mmHg}, 95 \% \mathrm{CI}=-7.17$ to $0.99 \mathrm{mmHg}, p=0.137)$. Moreover, the 257 funnel plots were also assessed (Figure S2).

258 We performed a meta-regression analysis using age as the moderator in the single meta-

259

260

261

262

263

264

265

266

267 regression to examine the heterogeneity of the present analysis. The result showed that the effect of music intervention on the anxiety level was not significantly confounded by age (slope $=$ $0.029, \mathrm{p}=0.723$; Figure 8).

\section{Discussion}

Our systematic review and meta-analysis support the beneficial effects of music intervention on anxiety during labor, in subjective and objective dimensions. We found that music intervention decreased anxiety score, HR, SBP, and DBP after the intervention ( $-2.40 \mathrm{SMD}, 3.04$ beats $/ \mathrm{min}$, $3.71 \mathrm{mmHg}$, and $3.54 \mathrm{mmHg}$, respectively).

268 The present meta-analysis comprehensively investigated the efficacy of music intervention on 269 anxiety during labor. Majority of the recent meta-analyses focus on pain (Smith et al. 2018) or 270 music intervention during pregnancy (Corbijn van Willenswaard et al. 2017). Other than pain, 271 high anxiety levels also cause multiple negative effects, such as elevated BP, increased cortisol 272 levels, elevated HR, slower wound healing, reduced immune response, increased infection risk 273 (Scott 2004), and enhanced anesthesia induction difficulty (Ozalp et al. 2003). Furthermore, 274 anxiety of being awake during operation has been shown to be the main reason for choosing 275 general anesthesia (Shevde \& Panagopoulos 1991). Higher risk and more adverse effects on the 
276 mother and child during sedation have been well known; therefore, non-pharmaceutical 277 intervention for anxiety during labor is important. Our survey focused on studies designed to 278 evaluate the effect of music intervention during labor process on anxiety level evaluated after 279 childbirth.

280 Our results are consistent with the previous studies related to the effects of music intervention on 281 lower anxiety in participants during labor (Chuang et al. 2018). Nevertheless, the analysis of 282 anxiety level by Chuang et al. only involved one study that evaluated the anxiety level using 283 VAS-A and one study that used the Zung SAS on primiparous women expected to undergo NSD. 284 In our analysis, we pooled six studies that evaluated the anxiety level with VAS-A, two studies 285 with SAS, two studies with STAI, and included pregnant women prepared to deliver via either 286 NSD or CS. We used strict inclusion criteria (only RCTs in the meta-analysis) and recent studies 287 rather than the old ones. Chuang et al. did not execute subgroup analysis as per the method of

288

289

290

291

292

293

294

295

296

297

298

299

300

301

302

303

304

305

306

307

308

309

310

311

312

313

314 delivery. In the current study, music intervention successfully lowered the anxiety score in women who delivered via NSD as well as those who underwent CS (Figure 3).

Reza et al. reported no significant decrease in the VAS-A score in CS participants (Reza et al. 2007); low level of preoperative anxiety in the study was considered a possible explanation (Nilsson et al. 2001). Our meta-analysis results revealed a significant decrease in the anxiety score, HR, and DBP after the music intervention in the CS group, but to lesser extent than in NSD group (SMD of anxiety score in CS group $=-0.70, \mathrm{SMD}=-4.69$ in NSD group; Figure 3 ), which is consistent with a previous meta-analysis, according to which, music during planned CS may improve the pulse rate and birth satisfaction score with small magnitude (Laopaiboon et al. 2009). Another study reported that participants undergoing surgery with local anesthesia who listened to music during surgery had significantly lower HR, anxiety, and BP (Mok \& Wong 2003).

Another possible reason for the ineffectiveness of the music intervention in the study by Reza et al may be related to the type of music. Participants did not have the opportunity to preoperatively choose the type of music and a culturally unfamiliar type of light music was used in their study. Perioperative music intervention changed the neurohormonal and immune stress response, especially if the participants selected the type of music by themselves in a study on participants undergoing day surgery (Leardi et al. 2007). Aldridge et al. declared that the effects of music were influenced by how much the subjects appreciated the type of music (Aldridge 1994). Women were suggested to develop individual preferences for the use of music and equipment.(Gentz 2001) In our meta-analysis, significant decreases in the anxiety score, HR, and DBP were found after the music intervention as compared to after placebo treatment, if the music type was chosen by the participants (Figure 4), which is consistent with the findings of the previous studies.

Several studies have evaluated the effect of music on the cardiovascular system (Koelsch \& Jancke 2015). The levels of BP and HR are reflected in terms of stress and anxiety other than subjective parameters (Koelsch \& Jancke 2015). The music intervention group showed 
315 significantly lower HR and BP levels in our meta-analysis with low heterogeneity. The outcomes 316 support the positive findings of subjective parameters.

317 The mechanism of music to affect physiological indicators of anxiety is based on the

318 psychophysiological theory (O'Callaghan et al. 2007). Music may relief anxiety by stimulating

319 pleasure, distracting concentration, and providing a bridge for meditation (Browning 2000;

320 Phumdoung \& Good 2003). Music can activate the release of endorphins, which are the body's

321 pain killers, to lower the unpleasant feelings and emotions and also lower the sympathetic

322 nervous system activity, HR, BP, respiratory rate, oxygen consumption, metabolic rate, skeletal

323

324

325

326

327

328

329

330

331

332

333

334

335

336

337

338

339

340

341

342

343

344

345

346

347

348

349

350

351

352

353 muscle tension, sweat gland activity, blood epinephrine level, plasma prednisone level, number of natural killer cells, neurohormonal stress, and immune stress (Arslan S 2008). This may explain the changes in the physiological indicators observed in the intervention group in our study.

The effect of music intervention on the anxiety score was not significantly confounded by age when age was used as a moderator in the single meta-regression. Rubertsson et al. reported that women $<25$ years of age had a higher risk of anxiety symptoms during early pregnancy. Other risk factors of anxiety included the use of different languages, lower education level, unemployment, nicotine use before pregnancy, and a self-reported psychiatric history of either depression or anxiety before the current pregnancy (Rubertsson et al. 2014). The mean participant age in our study ranged from 23.8 to 33.6 years. A mean participant age $<25$ years was only found in one study.

The strengths of our study included a relatively larger total study population than that in other reviews on similar topics and the lack of language restriction. Considering our results, there are great indications for clinical practice. Music is inexpensive, effective, safe, and easy to be used in daily clinical practice. Therefore, music interventions can be offered as a routine practice to women during labor.

There are certain limitations of this study. First, some subgroup analyses were not performed due to the lack of studies, such as those regarding music intervention time, and the time of outcome measurement. Second, the number of trials included was limited, making it difficult to execute more meaningful meta-regression analyses to examine the impact of variables that may affect the heterogeneity of the results. Third, the sample size of some included studies was small and did not provide details on the randomization processes. Fourth, the time of outcome measurement and music types in each study varied, thus potentially limiting the usability of some results. We attempted to select the result with a similar time of outcome measurement from each study; however, there remained high heterogeneity in the meta-analysis of the pooled anxiety scores after the intervention between the music intervention and the placebo groups, included in the subgroup analyses. The anxiety level changed largely during the active phase; therefore, when evaluating the treatment effects, the time of the assessment was important. Finally, the variation between these studies in terms of participant characteristics, intervention design, and time of outcome measurements should be considered. Further well-designed studies are needed to clarify 
354 the influences of music types, time of music intervention, and time of outcome measurement on

355

356

357

358

359

360

361

362

363

364

365

366

367

368

369

370

371

372

373

374

375

376

377

378

379

380

381

382

383

384

385

386

387

388

389

390

391

392

393

394

395

396

397

398

399

400

401

the effect of music intervention.

\section{Conclusions}

Thus music interventions during labor significantly reduce the anxiety scores and physiological indexes related to anxiety (HR, SBP, and DBP). Music interventions may be effective in reducing the anxiety levels during labor. Application in clinical routine may be advisable. Additional large RCTs focusing on the music types, time of music intervention, and time of outcome measurement are required to validate these findings.

\section{Acknowledgements}

The authors would like to thank Enago (www.enago.tw), the editing brand of Crimson Interactive Pvt., Ltd. for the English language review.

\section{References}

Aldridge D. 1994. Alzheimer's disease: rhythm, timing and music as therapy. Biomedicine and Pharmacotherapy 48:275281.

Arslan S ÖN, Özyurt F. 2008. Effect of music on preoperative anxiety in men undergoing urogenital surgery. Australian Journal of Advanced Nursing 26:46-54.

Blackburn K, Scott P, Wilson C, Lanier K, Borges A, Curtis E, and Mertz HL. 2011. The effects of music therapy on women's anxiety before and during cesarean delivery. Reproductive Sciences 18:374A. 10.1177/193371912011183s067

Bradt J, Potvin N, Kesslick A, Shim M, Radl D, Schriver E, Gracely EJ, and Komarnicky-Kocher LT. 2015. The impact of music therapy versus music medicine on psychological outcomes and pain in cancer patients: a mixed methods study. Supportive Care in Cancer 23:1261-1271. 10.1007/s00520-014-2478-7

Browning CA. 2000. Using music during childbirth. Birth 27:272-276.

Cardwell MS. 2013. Stress: pregnancy considerations. Obstetrical and Gynecological Survey 68:119-129. 10.1097/OGX.0b013e31827f2481

Chang S-C, and Chen C-H. 2005. Effects of music therapy on women's physiologic measures, anxiety, and satisfaction during cesarean delivery. Research in Nursing and Health 28:453-461. 10.1002/nur.20102

Choubsaz M, Rezavand N, Bayat A, Farhadi K, and Amirifard N. 2018. Comparison between the effect of ear plug and music in reducing anxiety in patients undergoing elective cesarean section under spinal anesthesia. Kuwait Medical Journal 50:37-42.

Chuang $\mathrm{CH}$, Chen PC, Lee CS, Chen CH, Tu YK, and Wu SC. 2018. Music intervention for pain and anxiety management of the primiparous women during labour: A systematic review and meta-analysis. Journal of Advanced Nursing. 10.1111/jan.13871

Corbijn van Willenswaard K, Lynn F, McNeill J, McQueen K, Dennis CL, Lobel M, and Alderdice F. 2017. Music interventions to reduce stress and anxiety in pregnancy: a systematic review and meta-analysis. BMC Psychiatry 17:271. 10.1186/s12888-017-1432-x

Egger M, Davey Smith G, Schneider M, and Minder C. 1997. Bias in meta-analysis detected by a simple, graphical test. BMJ 315:629-634.

Gentz BA. 2001. Alternative therapies for the management of pain in labor and delivery. Clinical Obstetrics and Gynecology 44:704-732.

Gokyildiz Surucu S, Ozturk M, Avcibay Vurgec B, Alan S, and Akbas M. 2018. The effect of music on pain and anxiety of women during labour on first time pregnancy: A study from Turkey. Complementary Therapies in Clinical Practice 30:96-102. 10.1016/j.ctcp.2017.12.015

Goodman JH. 2004. Postpartum depression beyond the early postpartum period. Journal of Obstetric, Gynecologic, and Neonatal Nursing 33:410-420. 
402

403

404

405

406

407

408

409

410

411

412

413

414

415

416

417

418

419

420

421

422

423

424

425

426

427

428

429

430

431

432

433

434

435

436

437

438

439

440

441

442

443

444

445

446

447

448

449

450

451

452

453

454

Gorkem U, Togrul C, Sahiner Y, Yazla E, and Gungor T. 2016. Preoperative anxiety may increase postcesarean delivery pain and analgesic consumption. Minerva Anestesiologica 82:974-980.

Hepp P, Hagenbeck C, Burghardt B, Jaeger B, Wolf OT, Fehm T, Schaal NK, and Group M. 2016. Measuring the course of anxiety in women giving birth by caesarean section: a prospective study. BMC Pregnancy and Childbirth 16:113. 10.1186/s12884-016-0906-z

Hepp P, Hagenbeck C, Gilles J, Wolf OT, Goertz W, Janni W, Balan P, Fleisch M, Fehm T, and Schaal NK. 2018. Effects of music intervention during caesarean delivery on anxiety and stress of the mother a controlled, randomised study. BMC Pregnancy and Childbirth 18:435. 10.1186/s12884-018-2069-6

Higgins JP, and Thompson SG. 2002. Quantifying heterogeneity in a meta-analysis. Statistics in Medicine 21:1539-1558. 10.1002/sim.1186

Higgins JP, Thompson SG, Deeks JJ, and Altman DG. 2003. Measuring inconsistency in meta-analyses. BMJ 327:557560. 10.1136/bmj.327.7414.557

Hornblow AR, and Kidson MA. 1976. The visual analogue scale for anxiety: a validation study. Australian and New Zealand Journal of Psychiatry 10:339-341. 10.3109/00048677609159523

Ikonomidou E, Rehnstrom A, and Naesh O. 2004. Effect of music on vital signs and postoperative pain. AORN Journal 80:269-274, 277-268.

Karkal E, Kharde S, and Dhumale H. 2017. Effectiveness of Music Therapy in Reducing Pain and Anxiety among Primigravid Women during Active Phase of First Stage of Labor. International Journal of Nursing Education 9:57-60. 10.5958/0974-9357.2017.00036.8

Koelsch S, and Jancke L. 2015. Music and the heart. European Heart Journal 36:3043-3049. 10.1093/eurheartj/ehv430

Kushnir J, Friedman A, Ehrenfeld M, and Kushnir T. 2012. Coping with preoperative anxiety in cesarean section: physiological, cognitive, and emotional effects of listening to favorite music. Birth (berkeley, calif). p 121127.

Lane D. 1992. Music therapy: a gift beyond measure. Oncology Nursing Forum 19:863-867.

Laopaiboon M, Lumbiganon P, Martis R, Vatanasapt P, and Somjaivong B. 2009. Music during caesarean section under regional anaesthesia for improving maternal and infant outcomes. Cochrane Database of Systematic Reviews:CD006914. 10.1002/14651858.CD006914.pub2

Leardi S, Pietroletti R, Angeloni G, Necozione S, Ranalletta G, and Del Gusto B. 2007. Randomized clinical trial examining the effect of music therapy in stress response to day surgery. British Journal of Surgery 94:943-947. 10.1002/bjs.5914

Lee S, Lim J, Woo N, Lee Y, Choi Y, and Park H. 2004. The Effects of Music on Maternal Anxiety and the Evaluation of Explicit and Implicit Memory during Cesarean Section. Korean Journal of Anesthesiology. p 341-346.

Li Y, and Dong Y. 2012. Preoperative music intervention for patients undergoing cesarean delivery. International Journal of Gynaecology and Obstetrics. p 81-83.

Liberati A, Altman DG, Tetzlaff J, Mulrow C, Gotzsche PC, Ioannidis JP, Clarke M, Devereaux PJ, Kleijnen J, and Moher D. 2009. The PRISMA statement for reporting systematic reviews and meta-analyses of studies that evaluate healthcare interventions: explanation and elaboration. BMJ 339:b2700. 10.1136/bmj.b2700

Liu Y, Chang M, and Chen C. 2010. Effects of music therapy on labour pain and anxiety in Taiwanese first-time mothers. Journal of Clinical Nursing 19:1065-1072. 10.1111/j.1365-2702.2009.03028.x

Mok E, and Wong KY. 2003. Effects of music on patient anxiety. AORN Journal 77:396-397, 401-396, 409-310.

Nilsson U, Rawal N, Unestahl LE, Zetterberg C, and Unosson M. 2001. Improved recovery after music and therapeutic suggestions during general anaesthesia: a double-blind randomised controlled trial. Acta Anaesthesiologica Scandinavica 45:812-817.

O'Callaghan C, Sexton M, and Wheeler G. 2007. Music therapy as a non-pharmacological anxiolytic for paediatric radiotherapy patients. Australasian Radiology 51:159-162. 10.1111/j.1440-1673.2007.01688.x

Ozalp G, Sarioglu R, Tuncel G, Aslan K, and Kadiogullari N. 2003. Preoperative emotional states in patients with breast cancer and postoperative pain. Acta Anaesthesiologica Scandinavica 47:26-29.

Phumdoung S, and Good M. 2003. Music reduces sensation and distress of labor pain. Pain Management Nursing 4:5461.

Reza N, Ali S, Saeed K, Abul-Qasim A, and Reza T. 2007. The impact of music on postoperative pain and anxiety following cesarean section. Middle East Journal of Anaesthesiology. p 573-586.

Rubertsson C, Hellstrom J, Cross M, and Sydsjo G. 2014. Anxiety in early pregnancy: prevalence and contributing factors. Arch Womens Ment Health 17:221-228. 10.1007/s00737-013-0409-0

PeerJ reviewing PDF | (2019:01:34693:2:0:NEW 10 Apr 2019) 
455

456

457

458

459

460

461

462

463

464

465

466

467

468

469

470

471

472

473

474

475

476

477

478
Scott A. 2004. Managing anxiety in ICU patients: the role of pre-operative information provision. Nursing in Critical Care 9:72-79.

Shevde K, and Panagopoulos G. 1991. A survey of 800 patients' knowledge, attitudes, and concerns regarding anesthesia. Anesthesia and Analgesia 73:190-198.

Siedliecki SL, and Good M. 2006. Effect of music on power, pain, depression and disability. Journal of Advanced Nursing 54:553-562. 10.1111/j.1365-2648.2006.03860.x

Simavli S, Gumus I, Kaygusuz I, Yildirim M, Usluogullari B, and Kafali H. 2014a. Effect of music on labor pain relief, anxiety level and postpartum analgesic requirement: a randomized controlled clinical trial. Gynecologic and Obstetric Investigation. p 244-250.

Simavli S, Kaygusuz I, Gumus I, Usluogulları B, Yildirim M, and Kafali H. 2014b. Effect of music therapy during vaginal delivery on postpartum pain relief and mental health. Journal of Affective Disorders 156:194-199. 10.1016/j.jad.2013.12.027

Smith CA, Levett KM, Collins CT, Dahlen HG, Ee CC, and Suganuma M. 2018. Massage, reflexology and other manual methods for pain management in labour. Cochrane Database of Systematic Reviews: John Wiley \& Sons, Ltd.

Smolen D, Topp R, and Singer L. 2002. The effect of self-selected music during colonoscopy on anxiety, heart rate, and blood pressure. Applied Nursing Research 15:126-136.

Wan Q, and Wen FY. 2018. Effects of acupressure and music therapy on reducing labor pain. International Journal of Clinical and Experimental Medicine 11:898-903.

Zhao M HX, Zhu C. 1999. Maternal anxiety and depression before and after childbirth. Curr Adv Obstet Gynecol 8:9596.

Zijlmans MAC, Beijers R, Riksen-Walraven MJ, and de Weerth C. 2017. Maternal late pregnancy anxiety and stress is associated with children's health: a longitudinal study. Stress 20:495-504. 10.1080/10253890.2017.1348497 
Figure $\mathbf{1}$ (on next page)

Schematic illustration of the literature search and the study selection criteria. CINAH, the Cumulative Index to Nursing and Allied Health; NTLTD, the Net worked Digital Library of Theses and Dissertations. 


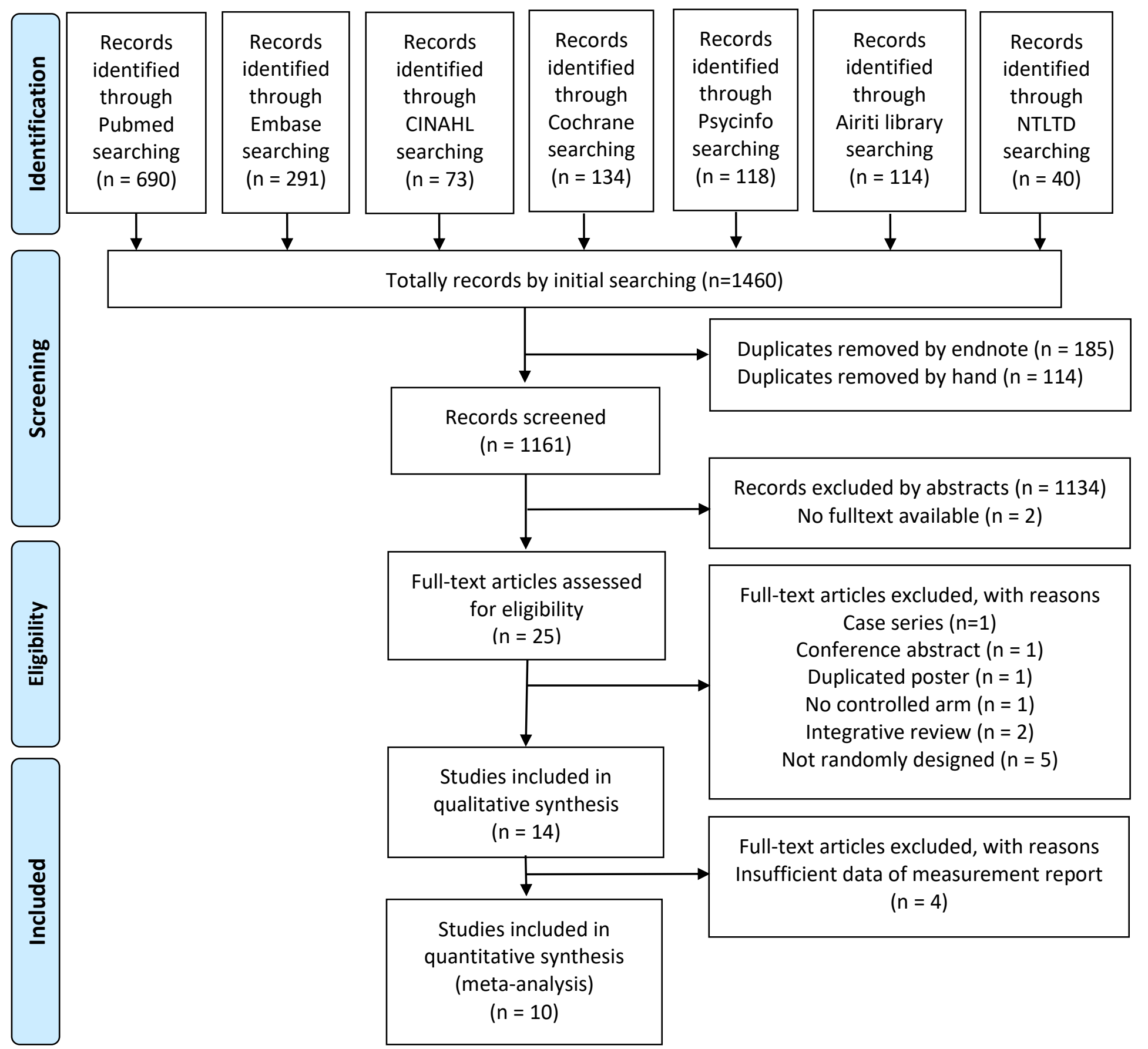


Figure 2

Forest plot of pooled anxiety scores after the intervention between the music intervention group and the placebo group (Overall meta-analysis)

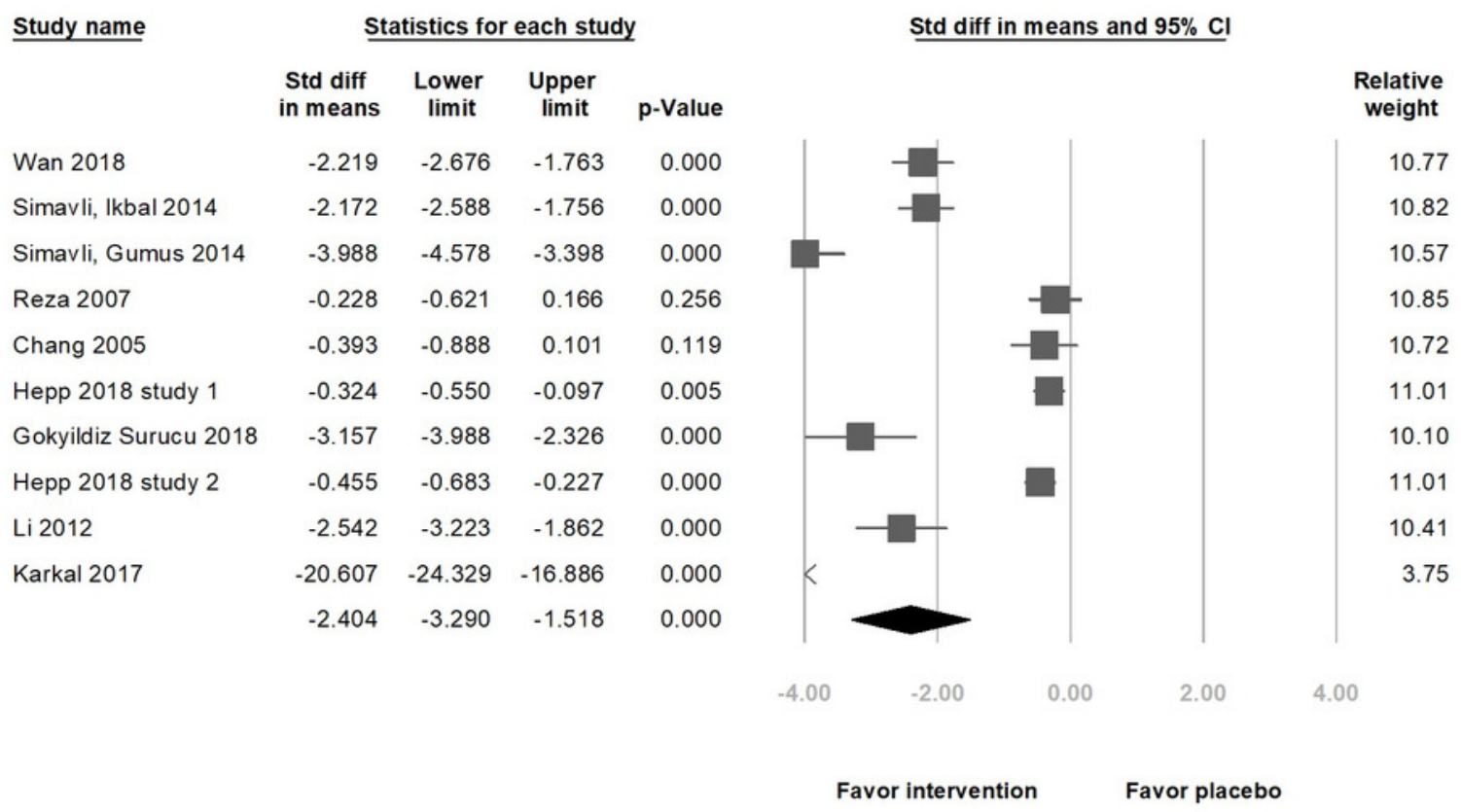


Figure 3

Forest plot of pooled anxiety scores after the intervention between the music intervention group and the placebo group (Subgroup analysis by methods of delivery).

\begin{tabular}{|c|c|c|c|c|c|}
\hline \multirow{2}{*}{$\begin{array}{l}\text { Group by } \\
\text { Delivery }\end{array}$} & \multirow[t]{2}{*}{ Study name } & \multicolumn{4}{|c|}{ Statistics for each study } \\
\hline & & $\begin{array}{l}\text { Std diff } \\
\text { in means }\end{array}$ & $\begin{array}{l}\text { Lower } \\
\text { limit }\end{array}$ & $\begin{array}{c}\text { Upper } \\
\text { limit }\end{array}$ & p-Value \\
\hline a. NSD & Wan 2018 & -2.219 & -2.676 & -1.763 & 0.000 \\
\hline a. NSD & Simavli, Ikbal 2014 & -2.172 & -2.588 & -1.756 & 0.000 \\
\hline a. NSD & Simavli, Gumus 2014 & -3.988 & -4.578 & -3.398 & 0.000 \\
\hline a. NSD & Gokyildiz Surucu 2018 & -3.157 & -3.988 & -2.326 & 0.000 \\
\hline a. NSD & Karkal 2017 & -20.607 & -24.329 & -16.886 & 0.000 \\
\hline a. NSD & & -4.689 & -6.280 & -3.098 & 0.000 \\
\hline b. CS & Reza 2007 & -0.228 & -0.621 & 0.166 & 0.256 \\
\hline b. CS & Chang 2005 & -0.393 & -0.888 & 0.101 & 0.119 \\
\hline b. CS & Hepp 2018 study 1 & -0.324 & -0.550 & -0.097 & 0.005 \\
\hline b. CS & Hepp 2018 study 2 & -0.455 & -0.683 & -0.227 & 0.000 \\
\hline b. CS & Li 2012 & -2.542 & -3.223 & -1.862 & 0.000 \\
\hline b. CS & & -0.701 & -1.181 & -0.222 & 0.004 \\
\hline
\end{tabular}

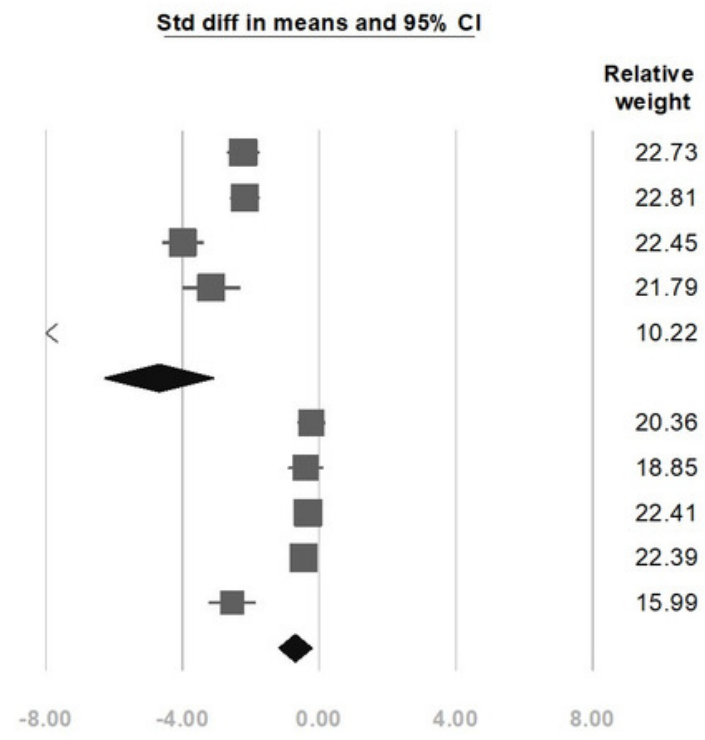

Favor intervention

Favor placebo 


\section{Figure 4}

Forest plot of pooled anxiety scores after the intervention between the music intervention group and the placebo group (Subgroup analysis by music types).

\begin{tabular}{|c|c|}
\hline$\frac{\text { Group by }}{\text { music type }}$ & Study name \\
\hline a. Patient choice & Wan 2018 \\
\hline a. Patient choice & Simavli, Ikbal 2014 \\
\hline a. Patient choice & Simavli, Gumus 2014 \\
\hline a. Patient choice & Chang 2005 \\
\hline a. Patient choice & Hepp 2018 study 1 \\
\hline a. Patient choice & Hepp 2018 study 2 \\
\hline $\begin{array}{l}\text { a. Patient choice } \\
\text { a. Patient choice }\end{array}$ & Li 2012 \\
\hline $\begin{array}{l}\text { b. Not patient choice } \\
\text { b. Not patient choice }\end{array}$ & Reza 2007 \\
\hline
\end{tabular}

\begin{tabular}{rrrr}
\multicolumn{5}{c}{ Statistics for each study } \\
$\begin{array}{c}\text { Std diff } \\
\text { in means }\end{array}$ & $\begin{array}{c}\text { Lower } \\
\text { limit }\end{array}$ & $\begin{array}{c}\text { Upper } \\
\text { limit }\end{array}$ & p-Value \\
-2.219 & -2.676 & -1.763 & 0.000 \\
-2.172 & -2.588 & -1.756 & 0.000 \\
-3.988 & -4.578 & -3.398 & 0.000 \\
-0.393 & -0.888 & 0.101 & 0.119 \\
-0.324 & -0.550 & -0.097 & 0.005 \\
-0.455 & -0.683 & -0.227 & 0.000 \\
-2.542 & -3.223 & -1.862 & 0.000 \\
-1.705 & -2.589 & -0.820 & 0.000 \\
-0.228 & -0.621 & 0.166 & 0.256 \\
-0.228 & -0.621 & 0.166 & 0.256
\end{tabular}

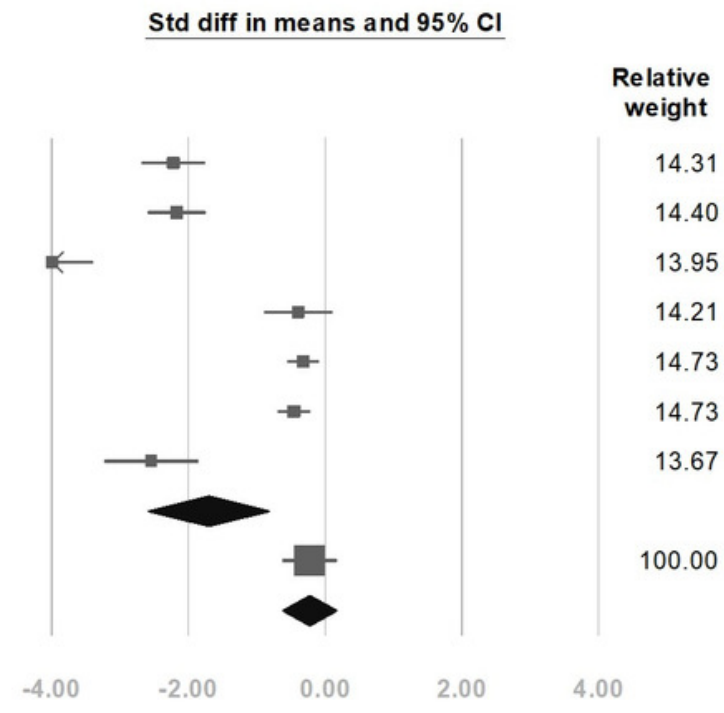


Figure 5

Forest plot of heart rate after the intervention between the music intervention group and the placebo group.

Study name

$\begin{array}{lrrrr} & \begin{array}{c}\text { Difference } \\ \text { in means }\end{array} & \begin{array}{c}\text { Lower } \\ \text { limit }\end{array} & \begin{array}{c}\text { Upper } \\ \text { limit }\end{array} & \text { p-Value } \\ \text { Simvali, Gumus 2014 } & -2.880 & -5.306 & -0.454 & 0.020 \\ \text { Chang 2005 } & -3.810 & -9.838 & 2.218 & 0.215 \\ \text { Lee 2004 } & -5.000 & -10.851 & 0.851 & 0.094 \\ \text { Hepp 2018 } & -2.540 & -5.703 & 0.623 & 0.116 \\ & -3.044 & -4.794 & -1.294 & 0.001\end{array}$

Difference in means and $95 \% \mathrm{Cl}$
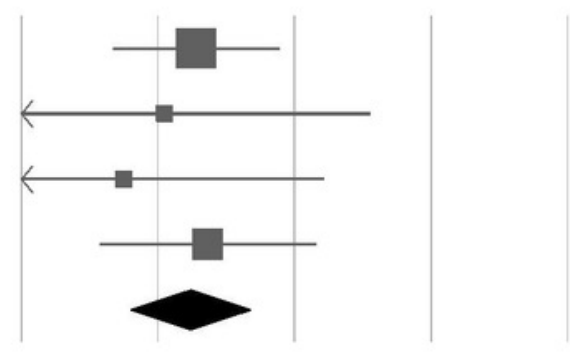

Relative weight

52.02

8.43

8.95

30.61 $\begin{array}{lllll}-8.00 & -4.00 & 0.00 & 4.00 & 8.00\end{array}$

Favor intervention Favor placebo 


\section{Figure 6}

Forest plot of systolic blood pressure after the intervention between the music intervention group and the placebo group.

Study name

$\begin{array}{lrrrr} & \begin{array}{c}\text { Difference } \\ \text { in means }\end{array} & \begin{array}{c}\text { Lower } \\ \text { limit }\end{array} & \begin{array}{c}\text { Upper } \\ \text { limit }\end{array} & \text { p-Value } \\ \text { Simvali, Gumus 2014 } & -5.540 & -9.020 & -2.060 & 0.002 \\ \text { Chang 2005 } & -4.660 & -12.294 & 2.974 & 0.232 \\ \text { Lee 2004 } & -6.000 & -11.072 & -0.928 & 0.020 \\ \text { Hepp 2018 } & -0.160 & -3.070 & 2.750 & 0.914 \\ & -3.708 & -7.070 & -0.346 & 0.031\end{array}$

Difference in means and $95 \% \mathrm{Cl}$

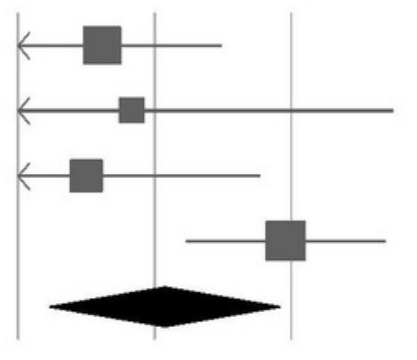

$\begin{array}{lllll}-8.00 & -4.00 & 0.00 & 4.00 & 8.00\end{array}$
Relative weight

30.43

13.57

22.27

33.74

Favor intervention Favor placebo 
Figure 7

Forest plot of diastolic blood pressure after the intervention between the music intervention group and the placebo group.

Study name

$\begin{array}{lrrrr} & \begin{array}{c}\text { Difference } \\ \text { in means }\end{array} & \begin{array}{c}\text { Lower } \\ \text { limit }\end{array} & \begin{array}{c}\text { Upper } \\ \text { limit }\end{array} & \text { p-Value } \\ \text { Simvali, Gumus 2014 } & -4.040 & -6.452 & -1.628 & 0.001 \\ \text { Chang 2005 } & -3.430 & -9.710 & 2.850 & 0.284 \\ \text { Lee 2004 } & -4.000 & -9.149 & 1.149 & 0.128 \\ \text { Hepp 2018 } & -2.540 & -5.703 & 0.623 & 0.116 \\ & -3.542 & -5.270 & -1.814 & 0.000\end{array}$

Difference in means and $95 \% \mathrm{Cl}$
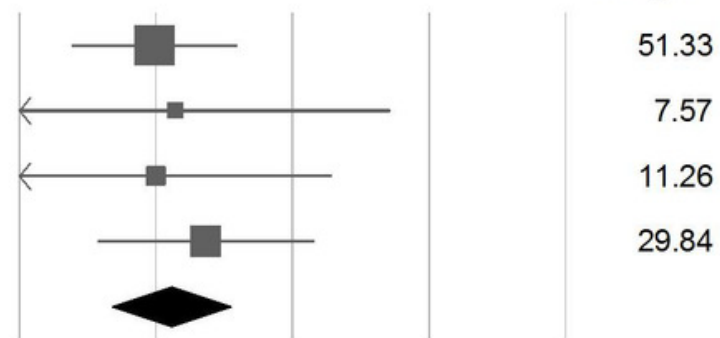

$\begin{array}{lllll}-8.00 & -4.00 & 0.00 & 4.00 & 8.00\end{array}$
Relative weight

51.33

7.57

29.84

Favor intervention Favor placebo 
Figure 8

Regression of anxiety scores on Age

\section{Regression of standardized mean difference on Age}

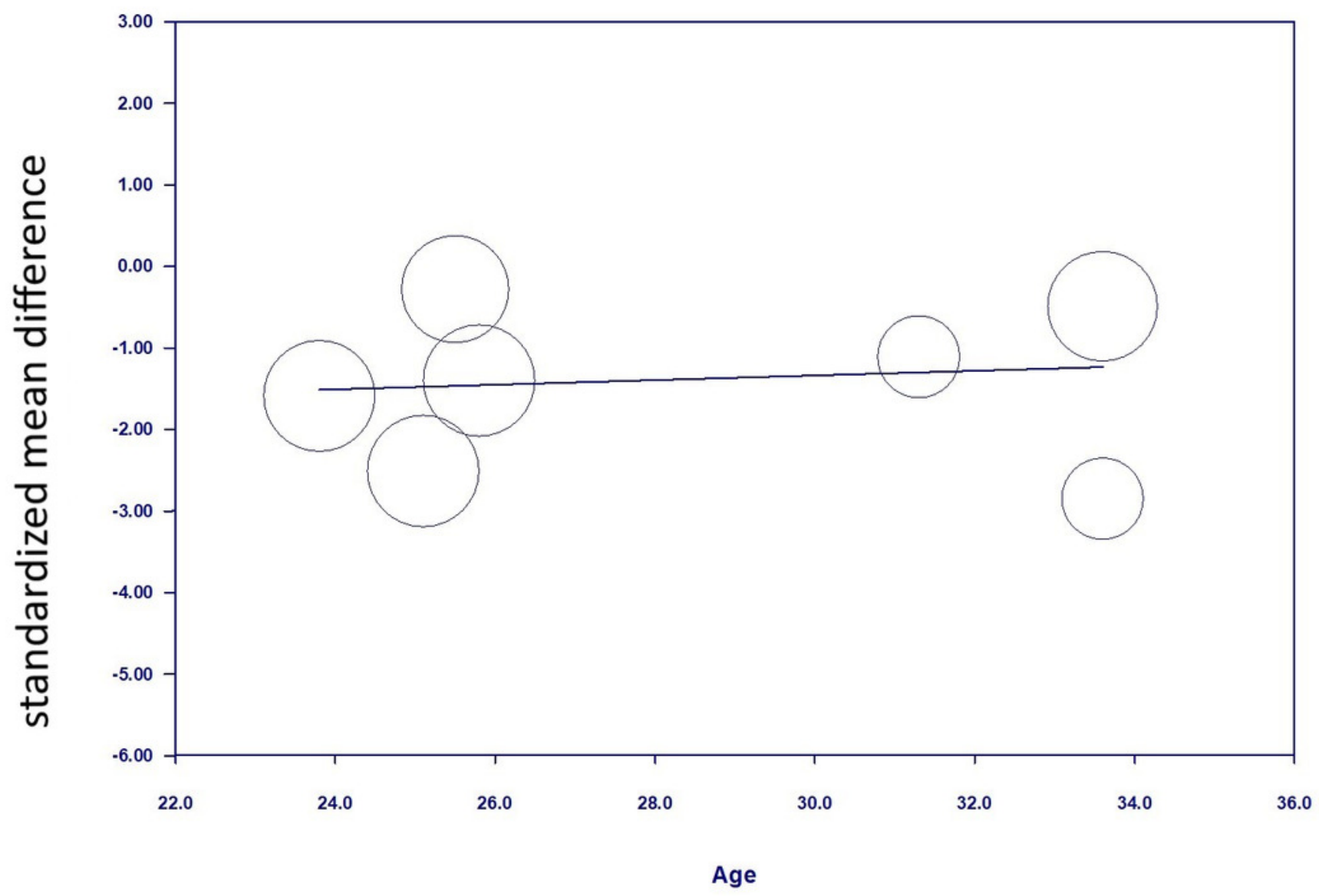




\section{Table $\mathbf{1}$ (on next page)}

Characteristics of randomized controlled trials investigating the effect of music intervention on anxiety during labor 


\begin{tabular}{|c|c|c|c|c|c|c|c|}
\hline Study & Country & Participants & $\begin{array}{l}\text { Age } \\
(\text { Mean } \pm \text { SD) } \\
(\text { I vs. C) }\end{array}$ & $\mathrm{I}: \mathrm{C}$ & Intervention & $\begin{array}{l}\text { Outcome } \\
\text { measures }\end{array}$ & findings \\
\hline $\begin{array}{l}\text { Choubsaz } \\
2018\end{array}$ & Iran & $\begin{array}{l}60 \text { low-risk } \\
\text { pregnant } \\
\text { women, ASA } \\
\text { class I and II } \\
\text { undergoing } \\
\text { elective CS }\end{array}$ & $\begin{array}{l}27.1 \pm 4.94 \text { vs. } \\
26.6 \pm 5.59\end{array}$ & $30: 30$ & $\begin{array}{l}\text { The "Motivation" } \\
\text { piece, a sedative } \\
\text { musical piece, was } \\
\text { played through a } \\
\text { headphone during } \\
\text { the surgery. }\end{array}$ & $\begin{array}{l}\text { STAI before and } \\
\text { after OP. }\end{array}$ & $\begin{array}{l}\text { Significant differences } \\
\text { between STAI in music } \\
(21.83 \pm 11.9 \text { vs. } 13 \pm \\
8.02) \text { and control } \\
\text { groups }(24.4 \pm 11.89 \text { vs. } \\
16.6 \pm 8.14) \text { pre and } \\
\text { post -test }(p=0.001) .\end{array}$ \\
\hline Hepp $2018^{*}$ & Germany & $\begin{array}{l}304 \text { low-risk } \\
\text { pregnant } \\
\text { women } \\
\text { undergoing } \\
\text { primary CS }\end{array}$ & $\begin{array}{l}33.5 \pm 5.4 \text { vs. } \\
33.7 \pm 5.4\end{array}$ & $154: 150$ & $\begin{array}{l}\text { Slow tempo music } \\
\text { from one (15 tracks) } \\
\text { of four self -selected } \\
\text { genres via } \\
\text { loudspeakers } \\
\text { started when } \\
\text { entering the OR. }\end{array}$ & $\begin{array}{l}\text { VAS-A, STAI, } \\
\text { salivary cortisol } \\
\text { and salivary } \\
\text { alpha amylase at } \\
\text { admission, skin } \\
\text { suture, and } 2 \mathrm{~h} \\
\text { after OP; HR, SBP } \\
\text { and DBP at skin } \\
\text { incision and } 2 \mathrm{~h} \\
\text { after OP. }\end{array}$ & $\begin{array}{l}\text { At skin suture, } \\
\text { significantly lower } \\
\text { STAI }(p=0.004) \text { and } \\
\text { VAS-A }(p=0.018) .2 \mathrm{~h} \\
\text { after OP, lower VAS-A } \\
(p=0.018) \text {; salivary } \\
\text { cortisol increased from } \\
\text { admission to skin } \\
\text { suture }(p=0.043) \text {; lower } \\
\text { SBP }(p=0.002) \text { and HR } \\
(p=0.049) \text { at skin } \\
\text { incision. }\end{array}$ \\
\hline $\begin{array}{l}\text { Gokyildiz } \\
\text { Surucu 2018* }\end{array}$ & Turkey & $\begin{array}{l}50 \text { low-risk } \\
\text { primigravid } \\
\text { women }\end{array}$ & NR & $25: 25$ & $\begin{array}{l}\text { Music was played } \\
\text { in Acemasiran } \\
\text { mode with earplugs } \\
\text { for } 3 \mathrm{~h} \text { ( } 20 \text { min of } \\
\text { listening with } 10- \\
\text { min breaks) during } \\
\text { the active phase. }\end{array}$ & $\begin{array}{l}\text { STAI, faces } \\
\text { anxiety scale } 30 \\
\text { min after } \\
\text { intervention, RR, } \\
\text { HR, SBP, DBP, } \\
\text { dilatation, } \\
\text { effacement, fetal } \\
\text { HR, period of } \\
\text { contraction, } \\
\text { frequency of } \\
\text { contraction at the } \\
\text { end of } 1^{\text {st }}, 3^{\text {rd }}, 5^{\text {th }}, \\
7^{\text {th }} h \text { of labor. }\end{array}$ & $\begin{array}{l}\text { The women who } \\
\text { listened to music } \\
\text { during labor had lower } \\
\text { anxiety levels, } \\
\text { evaluated the } \\
\text { labor as easier, had } \\
\text { longer periods of } \\
\text { contraction, and their } \\
\text { labor progressed faster. }\end{array}$ \\
\hline Wan $2018^{*}$ & China & $\begin{array}{l}119 \text { low-risk } \\
\text { primigravid } \\
\text { women, } \\
\text { singleton, and } \\
\text { expected to } \\
\text { have NSD }\end{array}$ & $\begin{array}{l}25.57 \pm 3.11 \\
\text { vs. } 26.02 \pm \\
2.90\end{array}$ & $60: 59$ & $\begin{array}{l}\text { Relaxing, soft and } \\
\text { regular rhythmic } \\
\text { music } \\
\text { recommended to } \\
\text { participants was } \\
\text { played with a 20- } \\
\text { min break for every } \\
2 \text { h during the } \\
\text { active phase. }\end{array}$ & $\begin{array}{l}\text { VAS-A }(1,4,8,16, \\
24 \text { h after } \\
\text { intervention). }\end{array}$ & $\begin{array}{l}\text { VAS-A scores } \\
\text { significantly different } \\
\text { from those in the } \\
\text { controls at all-time } \\
\text { points (all } p<0.05) .\end{array}$ \\
\hline Karkal 2017* & India & $\begin{array}{l}60 \text { primigravid } \\
\text { women who } \\
\text { were in the } \\
\text { active phase of } \\
\text { labor }\end{array}$ & NR & $30: 30$ & $\begin{array}{l}\text { Music was } \\
\text { administered in the } \\
\text { first stage of labor. }\end{array}$ & $\begin{array}{l}\text { Zung's SAS (pre- } \\
\text { test and post-test). }\end{array}$ & $\begin{array}{l}\text { The mean post-test } \\
\text { score of anxiety } \\
\text { between the } \\
\text { experimental and } \\
\text { control groups was } \\
40.01(p<0.001) \text {. }\end{array}$ \\
\hline $\begin{array}{l}\text { Simavli, } \\
\text { Gumus 2014* }\end{array}$ & Turkey & $\begin{array}{l}132 \text { low-risk } \\
\text { primigravid } \\
\text { women, } \\
\text { singleton, } \\
\text { expected to } \\
\text { have NSD }\end{array}$ & $\begin{array}{l}25.06 \pm 4.33 \\
\text { Vs. } 25.09 \pm \\
4.53\end{array}$ & $67: 65$ & $\begin{array}{l}\text { Self-selected music } \\
\text { (relaxing, regular } \\
\text { rhythmic patterns) } \\
\text { were played all the } \\
\text { time with } 20 \text {-min } \\
\text { break for every h } \\
\text { via headphones } \\
\text { since } 2 \mathrm{~cm} \text { cervical } \\
\text { dilatation to first } 2 \mathrm{~h}\end{array}$ & $\begin{array}{l}\text { VAS-A, SBP, DBP, } \\
\text { HR (before music, } \\
\text { latent phase, } \\
\text { active phase, } \\
\text { second stage and } \\
2 \text { h postpartum); } \\
\text { analgesic } \\
\text { requirement. }\end{array}$ & $\begin{array}{l}\text { A significantly lower } \\
\text { level of anxiety ( } p< \\
0.001) \text {, maternal } \\
\text { hemodynamics } \\
\text { and fetal HR }(p<0.01) \\
\text { in the interventional } \\
\text { group at all stages of } \\
\text { labor and analgesic } \\
\text { requirement }\end{array}$ \\
\hline
\end{tabular}


of the active phase.

$\begin{array}{lll}\text { Simavli, } & \text { Turkey } & 141 \text { low-risk } \\ \text { Ikbal 2014* } & & \text { primigravid } \\ & \text { women, } \\ & \text { singleton, } \\ & \text { expected to }\end{array}$

Kushnir 2012 Israel

60 low-risk

pregnant

women,

undergoing an

elective CS for

medical

reasons only

$\begin{array}{lll}\text { Li 2012* } & \text { China } & \begin{array}{l}\text { 60 low-risk } \\ \text { pregnant } \\ \text { women, ASA } \\ \text { class I and II, } \\ \text { undergoing } \\ \text { elective CS }\end{array} \\ & \\ \text { Blackburn } & \text { United } & \begin{array}{l}50 \text { low-risk } \\ \text { pregnant } \\ \text { women, } \\ \text { undergoing an } \\ \text { elective CS, } \\ \text { singleton. }\end{array}\end{array}$

$\begin{array}{clll}\text { Liu } 2010 \quad \text { Taiwan } & \text { 60 low-risk } & 26.63 \pm 4.02 \\ & \text { primigravid } & \text { vs. } 27.60 \pm \\ & \text { women, } & 4.34 \\ & \text { singleton, } \\ & \text { expected to } \\ & \text { have NSD. }\end{array}$

\begin{tabular}{|c|c|c|c|c|}
\hline Reza $2007^{*}$ & Iran & $\begin{array}{l}100 \text { low-risk } \\
\text { pregnant } \\
\text { women, ASA } \\
\text { class I, } \\
\text { undergoing } \\
\text { elective CS } \\
\text { under general } \\
\text { anesthesia }\end{array}$ & $\begin{array}{l}26 \pm 5.19 \text { vs. } \\
25 \pm 4.23\end{array}$ & $50: 50$ \\
\hline Chang $2005^{*}$ & Taiwan & $\begin{array}{l}64 \text { low-risk } \\
\text { pregnant } \\
\text { women, } \\
\text { undergoing } \\
\text { elective CS, }\end{array}$ & $\begin{array}{l}30.31 \pm 4.16 \\
\text { vs. } 32.31 \pm \\
4.48\end{array}$ & $32: 32$ \\
\hline
\end{tabular}

Self-selected music (relaxing, regular rhythmic) played all the time with a 20min break for every $2 \mathrm{~h}$ since $2 \mathrm{~cm}$ cervical dilatation to stage.

$32.0 \pm 3.97$ vs. $\quad 28: 32$ $32.13 \pm 4.79$

NR

$30: 30$

Self-chosen Chinese classical music was played for $30 \mathrm{~min}$ before OP and was continued after anesthesia.

NR

$25: 25$

Self-selected music provided through MP3 player with programmed genres of music administered for 30 minutes prior to and after their CS.

Self-chosen music (include classical, light, popular, crystal or Chinese religious music) was played at least 30 min during the latent phase and active phase.

Intra-OP music (soft instrumental, including 15 segments of a Spanish style guitar not selected by the patients).

Self-selected music (Western classical, new age, or Chinese religious music.) administered for at the end of the 3rd
VAS-A $(1,4,8,16$, $24 \mathrm{~h}$ postpartum), VAS-S $(2,12,24 \mathrm{~h}$ postpartum)

Mood states scale

2. Perceived threat of surgery scale 3. SBP, DBP, HR, RR

(before and after 40 min of music listening)

The Zung's SAS, total power, LF, $\mathrm{HF}$, and LF/HF ratio in HRV (at the preoperative visit and just before OP).

STAI after intervention.

VAS-A, finger temperature (before and after 30 min of music listening during the latent and active phases).

VAS-A immediately in PACU and at 0.5 , $1,2,4$, and $6 \mathrm{~h}$ postoperatively

VAS-A, SpO2, finger temperature, $\mathrm{RR}$, HR, SBP, DBP prior to postpartum $(p<0.001)$.

significantly lower postpartum anxiety at all-time intervals $(1,4$, 8,16 , and $24 \mathrm{~h}, \mathrm{p}=$ 0.001). Significantly lower satisfaction rate $(p=0.001)$.

Significant increase in positive emotions and a significant decline in negative emotions and perceived threat of the situation. Significant reduction in SBP, increase in DBP and RR.

The mean HRV was significantly less, the mean $\mathrm{HF}$ value was significantly increased, and the mean anxiety score was significantly decreased.

The intervention of patient-selected music before and after CS will reduce the anxiety levels in the patients undergoing CS $(p<$ 0.05).

The experimental group had significantly lower pain, anxiety and a higher finger temperature during the latent phase.

There were no significant differences in terms of the post-OP anxiety in PACU and at $0.5,1,2$ and 4 h postOP

Significantly lower anxiety level and a higher level of satisfaction regarding the CS. No significant 


\begin{tabular}{|c|c|c|c|c|c|c|c|}
\hline & & $\begin{array}{l}\text { singleton, } \\
\text { received } \\
\text { spinal or } \\
\text { epidural } \\
\text { anesthesia }\end{array}$ & & & $\begin{array}{l}\text { least } 30 \mathrm{~min} \text { from } \\
\text { the start of } \\
\text { anesthesia until the } \\
\text { end of OP. }\end{array}$ & $\begin{array}{l}\text { anesthesia, the } \\
\text { end of maternal } \\
\text { contact with the } \\
\text { neonate, and after } \\
\text { completion of the } \\
\text { skin suture }\end{array}$ & $\begin{array}{l}\text { differences were found } \\
\text { between the two } \\
\text { groups in any of the } \\
\text { physiological indexes. }\end{array}$ \\
\hline Lee $2004^{*}$ & Korea & $\begin{array}{l}50 \text { low-risk } \\
\text { pregnant } \\
\text { women } \\
\text { undergoing an } \\
\text { elective CS }\end{array}$ & $\begin{array}{l}28.1 \pm 7.0 \text { vs. } \\
29.7 \pm 5.1\end{array}$ & $25: 25$ & $\begin{array}{l}\text { Patients wore the } \\
\text { headphones as soon } \\
\text { as they entered the } \\
\text { OR and listened to } \\
\text { the music (the Four } \\
\text { Seasons Vivaldi and } \\
\text { other } 5 \text { songs (e.g., } \\
\text { lullaby-Mozart) } \\
\text { three times repeat). }\end{array}$ & $\begin{array}{l}\text { SBP, DBP, HR, } \\
\text { intra-OP } \\
\text { awareness, post-OP } \\
\text { explicit and } \\
\text { implicit memory, } \\
\text { plasma cortisol (1 } \\
\text { min before, } 1 \text { min } \\
\text { after, } 3 \text { min after } \\
\text { intubation; } 1 \text { min } \\
\text { after, } 10 \text { min after } \\
\text { delivery; } 5 \text { min } \\
\text { after extubation). }\end{array}$ & $\begin{array}{l}\text { Music significantly } \\
\text { decreased SBP and HR } \\
\text { at } 1 \text { min after } \\
\text { intubation and } 5 \text { min } \\
\text { after extubation, } \\
\text { increased hit ratio of } \\
\text { the implicit memory } \\
\text { test, decreased cortisol } \\
\text { at } 30 \text { min after } \\
\text { intubation and } 10 \text { min } \\
\text { after arriving in the } \\
\text { recovery room. }\end{array}$ \\
\hline$*$ & studies in & 1 in meta- & ysis. $\mathrm{Al}$ & iati & (in alphabetica) & order): ASA: A & nerican Society \\
\hline fo & or Anesthe & gy, C: con & , CS: cae & ian & tion, DBP: dias & lic blood press & re, h: hour, HF: \\
\hline lo & ow-frequen & power, HR: & heart rate & HRV & eart rate variab & ity, I: interv & tion, LF: low- \\
\hline 4 & requency & $r, \min : \mathrm{n}$ & ite, NR & 1 & d, NSD: no & spontaneo & delivery, OP: \\
\hline 5 & peration, $\mathrm{O}$ & operation ro & m, PACU: & ost-a & thesia care unit, & RR: respiratory & rate, SAS: self- \\
\hline 6 & ating anxi & ale, SBP: & stolic bl & $n r$ & , $\mathrm{SpO}_{2}:$ puls & hemoglobin o & gen saturation, \\
\hline 7 & TAI: Stat & t Anxiety I & entory, V & o. VI & analog scale, & AS-A: VAS fo & anxiety, VAS- \\
\hline 8 & : VAS for & faction & & & & & \\
\hline
\end{tabular}

